\title{
Assessment of cervicovaginal HCG and cervical length in prediction of labour
}

\author{
Noopur Mishra, Uzma Kausar \\ Correspondence: Dr Uzma Kausar, Assistant Professor, Department of Obstetrics and \\ Gynecology, MRA Medical College, Ambedkarnagar, UP, India; Email- \\ njmsonline@gmail.com
}

Distributed under Creative Commons Attribution-Share Alike 4.0 International.

\begin{abstract}
Objective: The purpose of this study is to evaluate cervicovaginal $\beta$ - HCG and cervical length as a diagnostic marker of preterm delivery. Methodology: This prospective study was conducted in the department of Obstetrics and Gynaecology, GSVM Medical College Kanpur from 2012 to 2013. The sample consisted of 100 women with singleton foetus with gestational age between 24-28 weeks. Study group $(\mathrm{n}=50)$ had risk factors for preterm delivery, and control group $(\mathrm{n}=50)$ had no risk factors. Results: Highest incidence of preterm labour occurred in age group of 22-26 years (56\%) and in multiparous women. Both range and mean $\beta$-HCG level in study group was significantly higher than control group. The mean cervical length (CL) in study group was significantly lower than control group. In study group, more cases were $\beta$ - HCG positive and had CL $<2.5 \mathrm{~cm}$ than control group and this difference was statistically significant. In study group, more cases who was $\beta$ - HCG positive and who had CL $<2.5 \mathrm{~cm}$ delivered preterm and this difference was statistically significant. Conclusion: Cervicovaginal $\beta$ - HCG and cervical length can prove to be useful markers in predicting preterm delivery.
\end{abstract}

Keywords: Preterm labour, $\beta$-HCG, cervical length.

Preterm labour is defined as and when labour is started after the $20^{\text {th }}$ week of pregnancy but before the 37 completed weeks. The incidence of preterm delivery is estimated to be around $10 \%$ of all deliveries leading to $75 \%-90 \%$ of prenatal morbidity and mortality. The aetiology of preterm birth is multifactorial. Although, in majority of cases the cause is unknown, intrauterine infection plays an important role in a high proportion of cases. Other causes include anomalies of conception, socio-economic factors such as poor maternal nutrition, poor antenatal care, physical and mental stress, short stature etc.

While preterm labour is associated with elevated levels of interleukin- 6 in amniotic fluid and foetal plasma sampled by cordocentesis, the association of maternal plasma interlekun-6 with preterm labour is less consistent. The widespread clinical use of amniotic fluid and umbilical cord blood is limited because of the invasive nature of amniocentesis. Therefore alternative non-invasive markers like cervicovaginal $\beta$-HCG and

Received: $21^{\text {st }}$ February 2017. Accepted: $2^{\text {nd }}$ April 2017.

Mishra N, Kausar U. Assessment of cervicovaginal HCG and cervical length in prediction of labour. The New Indian Journal of OBGYN. 2017; 4(1):71-6 
cervical length are being researched for detecting women at high risk of preterm delivery.

In the "pre-term" prediction study ${ }^{1}$, the most predictive markers were cervicovaginal fibronectin, cervical length $<10^{\text {th }}$ percentile and lower gestational age of previous preterm birth. Fibronectin assay is expensive and not widely available, so alternative markers like cervicovaginal HCG are being explored. Human chorionic gonadtrophin (HCG) is a glycoprotein hormone produced during pregnancy, that is made by the developing embryo after conception and latter by the syncytiotrophoblast (part of placenta) and secreted into the blood of both mother and fetus. HCG levels can first be detected by a blood test about 11 days after 12-14 days after conception by a urine test. HCG levels are double every 72 hours. The level reaches its peak in the first 8-11 weeks of pregnancy and then decline and level off for the remainder of the pregnancy.

Reduced cervical length in the second trimester is observed to increase the chance of preterm delivery. Ultrasound may be used to assess the length of cervix in women at high risk of preterm birth. Cervical length has been evaluated by Trans Vaginal Ultrasonography (TVS) in both low- risk and high risk women for prediction preterm birth. Various studies ${ }^{2,3}$ have been done to find the relationship between cervico-vaginal $\beta$-HCG and cervical length and risk of preterm delivery. With this background this study was conducted with the objective to evaluate the prediction of the preterm birth by level of cervicovaginal HCG and cervical length measured between 24-28 weeks of gestation in asymptomatic women having high risk of preterm birth.

\section{Material and Methods}

This prospective study was conducted in Upper India Sugar Exchange Maternity Hospital, department of Obstetrics and Gynaecology, GSVM Medical College, Kanpur from 2012-13 after taking permission from institutional ethical committee. A total of 100 pregnant women with singleton foetus having gestational age less than 28 weeks were studied. Fifty (50) were of the study group and 50 of the control group. Study group comprised of patients who had high risk factors for preterm delivery and control group was comprised of patients who had no risk factors. Informed consent was obtained from all the patients. At the initial preterm routine ANC visit, detailed history was taken from the pregnant female.

Inclusion criteria consisted of singleton pregnancy, gestational age less than 28 weeks, previous history of at least one prior preterm birth due to spontaneous preterm labour or premature rupture of membranes, no history of apparent genitourinary infections, patients with bad obstetric history, normal pre-pregnancy BMI and history of threatened abortion. Exclusion criteria consisted of multiple gestation, congenital malformation of uterus, current or planned cervical cerclage, uterine malformation, antepartum haemorrhage, obstetric complications needing iatrogenic preterm delivery (expect preterm rupture of membranes) and medical disorders.

Cervicovaginal $\beta$ HCG Assay (Between $24 \& 28$ weeks of gestation): Each woman underwent a speculum examination during which a sterile cotton tipped swab was placed first at external cervical os and then in posterior fornix and then instilled in a tube containing $0.75 \mathrm{ml}$ of sterile normal saline for dilution. This sample was stored at $70^{\circ} \mathrm{C}$, analysis in pathology lab by an ELISA test (Quantitative Radio immune assay).

Cervical Length Measurement by Transvaginal Ultrasonography (Between 24 and 28 weeks) was performed on the same patient after cervicovaginal HCG sampling. A condom covered endovaginal transducer was introduced into anterior fornix. Cervical length was measured three times from internal to the external os and the shortest length obtained was recorded.

Patients were kept in regular follow up and delivery and perinatal outcome was noted. Any incidence of preterm labour or premature rupture of membrane requiring admission or treatment was noted.

\section{Results}

Out of 100 cases, 50 cases belonged to study group and 50 cases belonged to control group. Cervicovaginal 
fluid $\beta$-HCG and cervical length by transvaginal ultrasound were measured in these 100 patients

Table 1: Mean $\beta$ - HCG level in both groups

\begin{tabular}{|c|c|c|c|}
\hline Group & $\begin{array}{ll}\beta- & \text { HCG } \\
\text { level }\end{array}$ & No (\%) & $\begin{array}{l}\text { Range } \\
(\mathrm{ml} \mathrm{U/ml})\end{array}$ \\
\hline \multirow[t]{2}{*}{$\begin{array}{l}\text { Study } \\
(\mathrm{n}=50)\end{array}$} & $\begin{array}{l}\text { Positive } \\
(\geq \mathbf{1 3 . 5})\end{array}$ & $35(70 \%)$ & $13.5-57.6$ \\
\hline & $\begin{array}{l}\text { Negative } \\
(<\mathbf{1 3 . 5})\end{array}$ & $15(30 \%)$ & $2.3-12.52$ \\
\hline $\begin{array}{l}\text { Control } \\
(\mathrm{n}=50)\end{array}$ & $\begin{array}{l}\text { Positive } \\
\text { Negative }\end{array}$ & $\begin{array}{l}8(16 \%) \\
42(84 \%)\end{array}$ & $\begin{array}{l}15.63-50.05 \\
1.10-10.15\end{array}$ \\
\hline
\end{tabular}

\begin{tabular}{|c|c|c|c|c|c|c|}
\hline iterion & Sensitivity & $95 \% \mathrm{CI}$ & Specificity & $95 \% \mathrm{Cl}$ & $+\mathrm{LR}$ & .LR \\
\hline$<2$ & 0.00 & $0.0-7.9$ & 100.00 & $93.5-100.0$ & & 1.00 \\
\hline$\leq 2.2$ & 22.22 & $11.2-37.1$ & 100.00 & $93.5-100.0$ & & 0.78 \\
\hline$\leq 2.3$ & 42.22 & $27.7-57.8$ & 98.18 & $90.3-100.0$ & 23.22 & 0.59 \\
\hline$\leq 2.4$ & 48.89 & $33.7-64.2$ & 94.55 & 84.9-98.8 & 8.96 & 0.54 \\
\hline$\leq 2.5$ & 66.67 & $51.0-80.0$ & 89.09 & 77.8-95.9 & 6.11 & 0.37 \\
\hline$\leq 2.6$ & 71.11 & $55.7-83.6$ & 81.82 & $69.1-90.9$ & 3.91 & 0.35 \\
\hline$\leq 2.7$ & 71.11 & $55.7-83.6$ & 80.00 & $67.0-89.6$ & 3.56 & 0.36 \\
\hline$\leq 2.8$ & 75.56 & $60.5-$ & 76.36 & 63.0 & 3.20 & 0.32 \\
\hline$\leq 2.9$ & 75.56 & $60.5-87.1$ & 72.73 & $59.0-83.9$ & 2.77 & 0.34 \\
\hline$\leq 3$ & 86.67 & 73.2 & .82 & 47.7 & 2.27 & 0.22 \\
\hline$\leq 3.1$ & 88.89 & 75.9-96.3 & 54.55 & $40.6-68.0$ & 1.96 & 0.20 \\
\hline$\leq 3.2$ & 100.00 & $92.1-100.0$ & 38.18 & $25.4-52.3$ & 1.62 & 0.00 \\
\hline$\leq 3.6$ & 100.00 & 92.1-100.0 & 0.00 & $0.0-6.5$ & 1.00 & 0.00 \\
\hline
\end{tabular}

statistically significant (95\% CI is 5.29-10.33). This implies that with $95 \% \mathrm{CI}$, if $\beta$ - HCG values are positive (raised), then there is at least 5.2 times more predisposition to preterm delivery. In the study group, range of $\beta$ - HCG level in $\beta$ - HCG positive cases was 13.5-57.06 $\mathrm{mlU} / \mathrm{ml}$, while in control group, range of $\beta$ - HCG level in $\beta$ - HCG positive cases was 15.63$50.05 \mathrm{mlU} / \mathrm{ml}$ (table 1). From the above table, it is obvious that a cervical length of $<2.5 \mathrm{~cm}$ should be taken as cut off point to predict preterm delivery as sensitivity $=66.67 \%$ and specificity $=89.09 \%$ are both high (table 2). At any other value of cervical length, either sensitivity becomes higher or specificity becomes very low. Similarly, $\beta$ - HCG value of $>13.5 \mathrm{mlU} / \mathrm{ml}$ was found as cut off point to predict preterm delivery (sensitivity $=71.11 \%$ and specificity $=81.82 \%)$. For Beta - HCG, area under the ROC curve (AUC) is 0.768 (95\% CI 0.673 to 0.847). For Cervical length, area under the ROC curve (AUC) is 0.860 (95\% CI 0.776 to 0.921) (table 3). Significant differences were found between the area under ROC curves $(\mathrm{P}=<0.05)$. In study group, range of cervical length was $2-3.6 \mathrm{~cm}$ and mean cervical length was $2.58 \mathrm{~cm}$ whereas in control group, range and mean cervical length was $2.2-3.6 \mathrm{~cm}$ between $24-28$ weeks gestation. The study group had the mean age $25.22 \pm 2.97 \mathrm{SD}$ years and control group $26.1 \pm 3.74$ SD years. Higher incidence of preterm labour occurred in multiparous women as compared to nulliparous females. In study group, range of $\beta$ - HCG level was $2.30-57.06 \mathrm{mlU} / \mathrm{ml}$ and mean $\beta$ - HCG level was $23.46 \pm 8.86 \mathrm{SD} \mathrm{mlU} / \mathrm{ml}$ whereas in control group, range and mean $\beta$ - HCG level was $1.02-50.05 \mathrm{mlU} /$ $\mathrm{ml}$ and $7.81 \pm 16.19 \mathrm{SD} \mathrm{mlU} / \mathrm{ml}$ respectively. Both range and mean $\beta$ - HCG level in study group was significantly higher than control group $(\mathrm{t}=5.997, \mathrm{P}<$ 0.0001). In study group, more cases were $\beta$ - HCG positive than control group and this difference was and 3.11 respectively. Thus, mean cervical

Table 3: Comparison of ROC curves

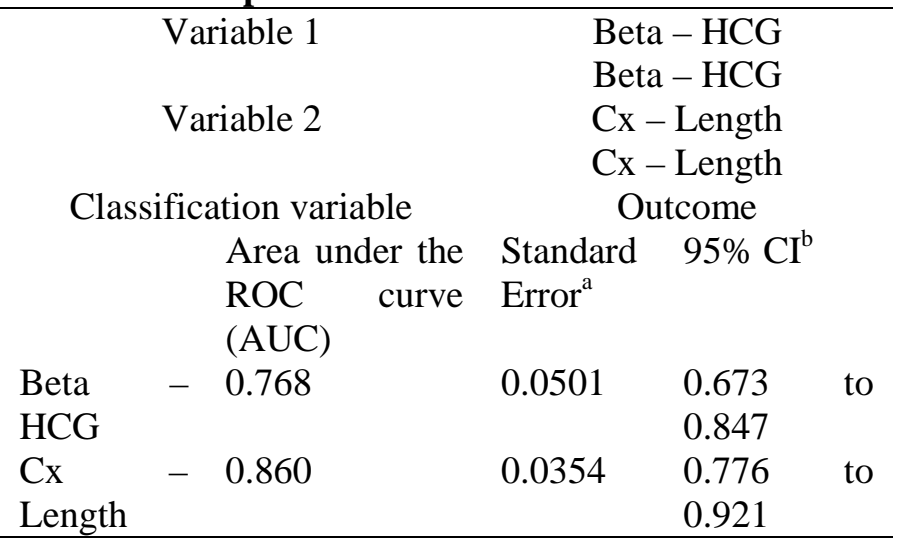


Table 4: Pairwise comparison of ROC curves

\begin{tabular}{ll}
\hline Beta $-\mathrm{HCG} \sim \mathrm{Cx}$ _Length & \\
Difference between areas (AUC) $^{\mathrm{S}}$ & 0.0915 \\
Standard Error $^{\mathrm{c}}$ & 0.0386 \\
95\% Confidence Interval & 0.0159 to 0.167 \\
Z statistic & 2.373 \\
Significance level & $\mathrm{P}=0.0176$ \\
\hline
\end{tabular}

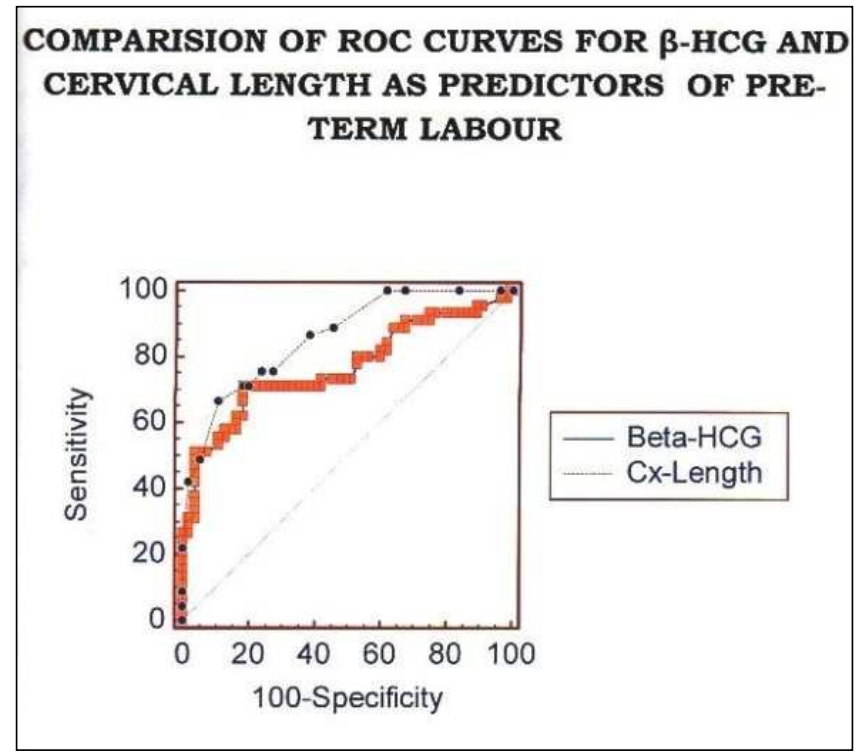

Figure 1: Comparison of ROC curves for Beta HCG and cervical length as predictors of pre-term labour group, more cases had $\mathrm{CL}<2.5 \mathrm{~cm}$ than control group and this difference was statistically significant. A higher proportion of patients who had $\mathrm{CL}<2.5 \mathrm{~cm}$ delivered preterm (38\%) as compared to those who had $\mathrm{CL} \geq 2.5 \mathrm{~cm}$ delivered preterm (34\%).

\section{Discussion}

In our study, age distribution of sample was compared in the study and control groups. Results showed highest incidence of preterm labour in the cases of 22-26 years age group. Similar results (25-30 years) have been reported by Radhanpuri et al ${ }^{4}$. In the present study, the higher incidence of preterm labour had occurred in multiparous women (58\%) as compared to the nulliparous and primiparous women. This was in contrast to a study by Marisa et $\mathrm{al}^{5}$ the highest incidence of preterm labour had occurred in nulliparous women.

In the present study, the most common gestational age group for preterm delivery was 32-34 weeks. This is comparable to the study by Das et al ${ }^{6}$ where $19.2 \%$ of total preterm births were between 28-32 weeks of gestation, $15.8 \%$ preterm babies were between $32-34$ weeks of gestation and $65 \%$ babies were 34-37 weeks of gestation. Maximum number of women (48.5\%) having preterm labour were in the gestational age group of 34-36 weeks in another study by Singh et al ${ }^{7}$.

From this study, it is

Table 5: Pregnancy outcome according to $\beta$-HCG cut off and cervical length

\begin{tabular}{llllll}
\hline Categories & & \multicolumn{2}{c}{ Study group $(\mathbf{N}=50)$} & \multicolumn{2}{c}{ Control group (N=50) } \\
& & Preterm & Term & Preterm & Term \\
& & $\mathbf{N}(\%)$ & $\mathbf{N}(\%)$ & $\mathbf{N}(\%)$ & $\mathbf{N}(\%)$ \\
\hline \multirow{2}{*}{-HCG } & Positive $(\geq 13.5)$ & $29(58 \%)$ & $6(12 \%)$ & $4(8 \%)$ & $3(6 \%)$ \\
& Negative $(<13.5)$ & $7(14 \%)$ & $8(16 \%)$ & $6(12 \%)$ & $37(74 \%)$ \\
CL in cm & CL $\geq 2.5$ & $17(34 \%)$ & $11(22 \%)$ & $6(12 \%)$ & $41(82 \%)$ \\
& CL $<2.5$ & $19(38 \%)$ & $3(6 \%)$ & $3(6 \%)$ & 0 \\
\hline
\end{tabular}
obvious that a $\beta$ - HCG value of $>13.5 \mathrm{mlU} / \mathrm{ml}$ should be taken as cut off point to predict preterm delivery as sensitivity $(71.11 \%)$ and specificity $(81.82 \%)$ are both high. At any other value of length in study group was significantly lower than control group. In study group, more cases who were $\beta$ HCG positive delivered preterm as compared to those $\beta$-HCG negative and this difference was statistically significant. In study group 28 cases had CL $\geq 2.5 \mathrm{~cm}$ $(56 \%)$ and 22 cases (44\%) cases had $C L<2.5 \mathrm{~cm}$ whereas in control group 47 cases $(94 \%)$ had $\mathrm{CL} \geq 2.5$ $\mathrm{cm}$ and 3 patients had $\mathrm{CL}<2.5 \mathrm{~cm}(6 \%)$. Thus in study
$\beta$-HCG, either sensitivity becomes low or specificity becomes low. Present study is comparable with other studies in terms of $\beta$-HCG cut off value, sensitivity and specificity mentioned in the

table 6 and 7.

From this study, it is also obvious that a cervical length of $<2.5 \mathrm{~cm}$ should be taken as cut off point to predict preterm delivery as sensitivity $(66.67 \%)$ and specificity (89.09\%) are both high. At any other value 
Table 6: Comparision with other studies in terms of $\beta$-HCG cut off value

\begin{tabular}{ll}
\hline Study & $\begin{array}{l}\boldsymbol{\beta}-\mathbf{H C G} \text { cut off value } \\
(\mathbf{m l U} / \mathbf{m l})\end{array}$ \\
\hline${\text { Bagga R et al }(2010)^{2}}^{2}$ & $45 \mathrm{mlU} / \mathrm{ml}$ \\
Adhikari K et al $(2009)^{3}$ & $77.8 \mathrm{mlU} / \mathrm{ml}$ \\
Sak et al $(2010)^{10}$ & $75 \mathrm{mlU} / \mathrm{ml}$ \\
Ranjbar M et al $(2012)^{11}$ & $22.5 \mathrm{mlU} / \mathrm{ml}$ \\
Present study & $13.5 \mathrm{mlU} / \mathrm{ml}$ \\
\hline
\end{tabular}

of cervical length, either sensitivity becomes higher but specificity becomes very low. In a study conducted by Crane JM et al ${ }^{8}$ the ability of cervical length measured by transvaginal ultrasonography predicted spontaneous preterm birth. The most common cervical length cutoff was $<25 \mathrm{~mm}$. Using this cut-off to predict spontaneous preterm birth at $<35$ weeks, transvaginal

\section{Table 7: Comparision of studies in terms of} sensitivity and specificity

\begin{tabular}{|c|c|c|}
\hline Study & Sensitivity & Specificity \\
\hline Garshasbi A et al (2004) $^{12}$ & $78.75 \%$ & $97 \%$ \\
\hline Adhikari K et al (2009) ${ }^{3}$ & $83.3 \%$ & $85.8 \%$ \\
\hline Bagga R. et al $(2010)^{2}$ & $95.8 \%$ & $73.7 \%$ \\
\hline Sak et al (2010) ${ }^{10}$ & $71.6 \%$ & $91.6 \%$ \\
\hline Ranibar M et al (2012) & $97 \%^{11}$ & $76 \%$ \\
\hline Present Study & $71.11 \%$ & $81.82 \%$ \\
\hline
\end{tabular}

ultrasonography at $<20$ weeks' gestation revealed LR+ 4.31 (95\% CI 3.08-6.01); at 20-24 weeks, LR+ 2.78 (95\% CI, 2.22-3.49); and at >24 weeks, LR+ $=4.01$ (95\% CI 2.53-6.34). This is comparable to the present study, taking cervical length $<2.5 \mathrm{~cm}$ as cut off (measured between 24-28 weeks of gestation) LR+ = 6.11 (95\%CI, 55.7-83.6). According to a study by Hoesli I et al ${ }^{9}$, a length of $25 \mathrm{~mm}$ or less at 28-30 weeks of gestation is associated with a significantly increased incidence of preterm. These observations were consistent with our study that also concluded that cervical length $<2.5 \mathrm{~cm}$ at $24-28$ weeks of gestation is a significant predictor of preterm birth.

\section{Conclusion}

Cervicovaginal $\beta$ - HCG and cervical length can prove to be useful markers in predicting preterm delivery. Further more studies with a larger database are required to confirm the findings of this study that raised $\beta$ - HCG levels and decreased cervical length can be used as a diagnostic marker for preterm delivery.

\section{Conflict of interest: None. Disclaimer: Nil.}

\section{References}

1.Mercer BM, Goldenberg RL, Meis PJ, Moawad AH, Shellhaas C, Das A, et al. The Preterm Prediction Study: prediction of preterm premature rupture of membranes through clinical findings and ancillary testing. Am J Obstet Gynecol. 2000; 183(3):738-45.

2.Bagga R, Takhtani M, Suri V, Adhikari K, Arora S, Bhardwaj SL. Cervical Length and Cervicovaginal HCG for prediction of preterm birth in women with signs and symptoms of preterm labour. J Obstet Gynaecol. 2010; 30(5):451-5.

3.Adhikari K, Bagga R, Suri V, Arora S, Masih S: Cervical length and cervicovaginal HCG in prediction of pretrm labour. Arch Gynaecol Obstet. 2009; 280 (4): 58572.

4.Radhanpuri F, Desai DA, Sharma J, Kaur P. Preterm birth and its outcome. Int J Reprod Contracept Obstet Gynecol. 2014; 3: 153-7.

5.Ip M, Peyman E, Lohsoonthorn V, Williams MA. A Case-Control Study of Preterm Delivery Risk Factors According to Clinical Subtypes and Severity. The journal of obstetrics and gynaecology research. 2010; 36(1): 3444.

6.Das A, Panda S, Ahanthem SS, Sourabh GD, Bhanu Pratap SG. Preterm Birth: Analysis of Risk Factors and Neonatal Outcome Gynecology and Obstetrics Case report. 2015;1(1):1-5

7.Singh U, Singh N, Seth S. A prospective analysis of etiology and outcome of preterm labor. J Obstet Gynecol India. 2007; 57(1) : 48-52

8.Crane JM, Hutchens D. Use of transvaginal ultrasonography to predict preterm birth in women with a history of preterm birth. Ultrasound Obstet Gynecol. 2008; 32 (5): 640-5.

9.Hoesli I, Tercanli S, Holzgreve W. Cervical length assessment by ultrasound as a predictor of preterm labour-is there a role for routine. BJOG. 2003; 110 (Suppl 20):61-5. 
10.Sak M, Sak S, Gul T. Beta-Human chorionic gonadotropin concentrations in cervicovaginal secretions as an early marker of preterm delivery. Experimental Journal of clinical and investigations. 2010; 1(1):16-20.

11.Ranjbar M, Tehranian N, Kazemnejad A, Ziaei S. A survey of -HCG in Cervicovaginal Secretions as a predictor of preterm delivery. Annals of Biological Research. 2012; 3 (10) : 4644 -49.

12.Garshasbi A, Ghazanfari T, Faghihzadeh S. Betahuman chorionic dgonadotropic in cervicovaginal secretions and preterm delivery. Int J Gynaecol Obstet. 2004; 86 (3): 358-64.

Noopur Mishra ${ }^{1}$, Uzma Kausar ${ }^{2}$

${ }^{1}$ Assistant Professor, Department of Obstetrics and Gynecology, MRA Medical College, Ambedkarnagar, UP, India; ${ }^{2}$ Assistant Professor, Department of Obstetrics and Gynecology, MRA Medical College, Ambedkarnagar, UP, India. 